\title{
Using Multimedia in Teaching Agricultural Machinery Subject through Cloud Computing: A Case Study of Sot Technical Training Institute -Bomet County, Kenya
}

\author{
Lincoln Langat \\ Computing Department \\ Jomo Kenyatta University of \\ Agriculture and Technology
}

\author{
Waweru Mwangi \\ Computing Department \\ Jomo Kenyatta University of \\ Agriculture and Technology
}

\author{
Calvins Otieno \\ Computing Department \\ Jomo Kenyatta University of \\ Agriculture and Technology
}

\begin{abstract}
The main aim of the Project was to incorporate ICT concepts in teaching Agricultural Machinery subject through Cloud Computing. The project entailed e-content development in line with the established curriculum for training Diploma level students in Technical Institutions in Kenya. The first objective outlined the utilization of diverse multimedia - audio, text, videos and graphics to enhance comprehension of the operating principle of diverse agricultural machinery. The project recognized that this made learners more interested and provoked participation in the teaching-learning process. The second objective identified appropriate multimedia for the various topics of training in the subject. The third objective involved selection of appropriate Learning Management System. For this project, Moodle was identified as the most appropriate [1]. The e-content could be accessed by both learners and trainers via the Cloud. The fourth objective was to test the functionality of the adopted system as used in teaching Agricultural Machinery subject. This was done by generating system reports and analyzing the usage.
\end{abstract}

\section{General Terms}

Curriculum, Agricultural machinery, Kenya Institute of Curriculum Development, Technical Vocational Education \& Training.

\section{Keywords}

Cloud computing, e-content, Multimedia, Learning Management System

\section{INTRODUCTION}

Media is the plural of medium referring to channel of conveying a message to a group or mass audience. Multimedia has diverse definitions which all revolve around utilization of various channels of communication. This project adopts that put forward by [2] as use of multiple modalities such as text, images, drawings (graphics), audio (including speech), animation and video together with interactivity to communicate. Multimedia production involves combination of various forms of media to a single output. Digital media is electronic media that entails use of computers to produce games, simulations, presentations, tutorials and web pages [3].

Learning Management System is web-based application software with relational database that connects learners to learning content, learner to learner interaction, course guidelines and evaluation techniques [4]. It enables registration of users, tracking of courses and produces various reports to the management [5]. Most of the Learning Management Systems have common features that trainers can use to share learning content as well as enable interaction with their trainees both asynchronously and synchronously [6].

The Technical Education curricula entail Artisan, Craft, and Diploma courses in various fields. Agricultural Machinery subject being taught in Technical Institutions as per the Kenya Institute of Curriculum Development (KICD) syllabus encompasses three sub units namely; Agricultural machinery, Tractors and Workshop Technology. The agricultural machines include ploughs, cultivators, sprayers, planters, mowers, rakes, hay balers, forage harvesters, hammer mills, feed mixers, grain driers and combine harvesters. Tractor units taught include types of engines, engine operation, power transmission, torque conversion and electrical systems.

This project focused on sampled machinery and tractor parts. The training was best achieved by blended pedagogical approach to enable trainer -trainee direct interaction and hands-on experience in the workshop for practical experience which is compulsory in engineering field. The Cloud Computing approach enhances the classroom interaction by enabling learners access e-content presented through multimedia for further interaction any time anywhere.

\section{LITERATURE REVIEW}

\subsection{Types of multimedia}

The three common classification of multimedia are interactive, hyperactive and linear multimedia. Interactive multimedia enables users to control what and when the elements can be delivered. Hypermedia provides users with links for navigation to related e-content. For linear multimedia, the users must watch from the start to the end whereas for non-linear, the user can select different stages of the e-content [7]. In the project, utilization of all the above was essential in teaching various topics of agricultural machinery.

\subsection{Appropriate multimedia in the teaching and learning process}

The teacher is at liberty to select the most appropriate multimedia for a given topic and at times, a combination may be required to deliver the e-content. Other research has pointed out that learners acquire more knowledge when words and graphics are used than from words alone [8]. According to [9], multi-sensory learning helps learners to interpret the information in a number of ways hence making learning richer and motivating.

\subsubsection{Text}

Since text is the most easily accessible means of communicating with learners, the researcher used it to avail 
learning content in form of notes in PDF format. Text is used to communicate ideas and messages in multimedia presentation. MS-word or other word processing software such as Open Office may be used to develop text. The text can be in different types of font, style, colour and size depending on the presentation being made.

According to [10], using multimedia in education enhances productivity and retention rate as people can remember $20 \%$ of what they see, $40 \%$ of what they see and hear, but about $75 \%$ of what they see, hear and do simultaneously.

In concluding his commentary, [11] pointed out that learners are able to benefit from multimedia differently. For instance, using text or narrations with diagrams may put high load on working memory of novice learners unlike experienced learners.

According to [12], various studies have been undertaken on the multimedia principles of learning. In his study on the learner's preference of multimedia design, he concluded that learners overwhelmingly preferred multiple (text +images +narration) approach in teaching.

\subsubsection{Audio}

Audio may be presented in three types -Music, narrations or Voice over and sound effects [13]. Speech/narration is a powerful means of communication particularly when given by an orator. However, to describe a tractor to a learner may be difficult for one who has never seen it. It may require more mental effort to perceive the concept and requires more concentration on the part of the listener [14]. This Project made use of combinations, for instance a running engine explanation may need to be accompanied by running engine sound.

\subsubsection{Animation}

Animation may be defined as a pictorial presentation displaying apparent movement of objects generated from drawings or other simulation methods [15]. The resultant effect from a series of pictures or frames with a time factor gives a visual illusion of actual activity [13]. The project used this approach to explain hidden details of machinery operations such as engine, gearbox, and baler twining among others.

In concluding their research, [16] pointed out that animated instructions are more effective in teaching complex practical skills whereas static graphics are suitable for teaching processes. While concluding his research, Betrancourt pointed out that effective animation needs to invoke the five principles namely- apprehension, interactivity, congruence, flexibility and attention guiding principles. Learning may be impaired when irrelevant content is included [17].

\subsubsection{Visual}

The visuals can be static (graphics) or motion (video). The static images may be 2-dimensional or 3-dimensional [13]. Old photos can be digitized using scanners and once it is in the computer, it can be cropped, enhanced and edited as required then stored [14]. Also drawn diagrams were used. A gearbox operation may require narration with visual aid. This project utilized photos (images) of machinery and equipment from the internet and those taken using camera or mobile phone to be used in teaching.

\subsubsection{Static graphics}

The trainer can take photos of machinery and equipment using camera or mobile phone to be used in teaching. A photo is a representation of a real object whereas a diagram is a static picture of a drawn (or simulated) object [15]. According to [16], different types of instructional goals demands different types of graphics. For example, facts require organizational and representational graphics, principles require interpretive and transformational graphics, process requires interpretive, relational and transformational graphics, concepts require organizational, interpretive and representational graphics, and procedure instruction can best by taught using transformational graphics. To explain the power flow in the manual gearbox with gears in neutral position, graphics were used and was best achieved with narrations.

The Figure 1 diagram can be accessed through the following link-

https://www.google.com/search?q=manual+gearbox+diagram \&tbm=isch\&source $=$ iu \&ict $=1 \&$ fir $=$ gse 3 ndHHDZHoDM $\% 2$ 53A\%252C63t9LKOJ16OjfM\%252C_\&usg=_6R1Mbpzu9 WiZD3WjyUsI0h1-

g_k\%3D\&sa=X\&ved=0ahUKEwjq0_62v77bAhUKPBQKHfa AAesQ9QEIKTAA\#imgrc=gse3ndHHDZHoDM:

\section{Figure 1: Manual gearbox in neutral position}

To outline how a reversible plough operates, the following graphic was used. The plough has two sets of bottoms with the headstock, Indexing mechanism, the standard, mouldboards and the beam.

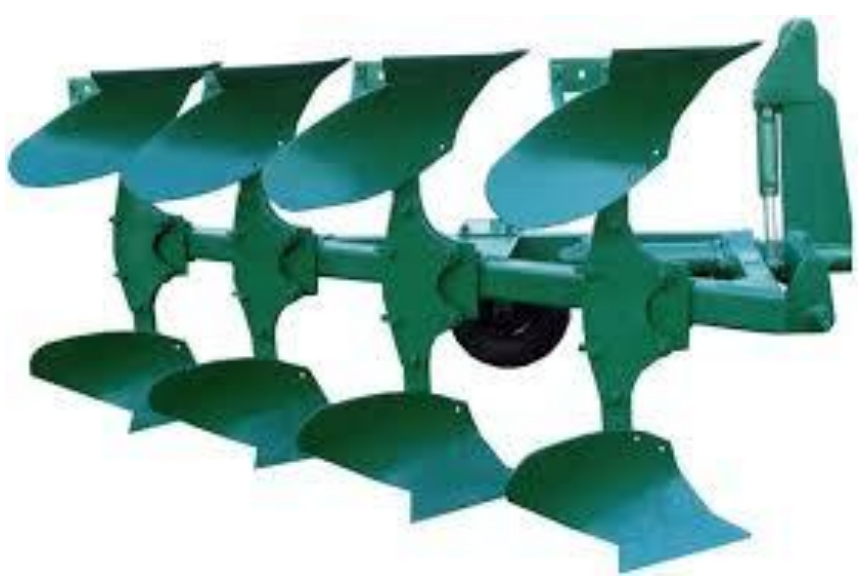

Figure 2: Reversible plough

To explain the crop flow in a forage harvester, the following graphic was used.

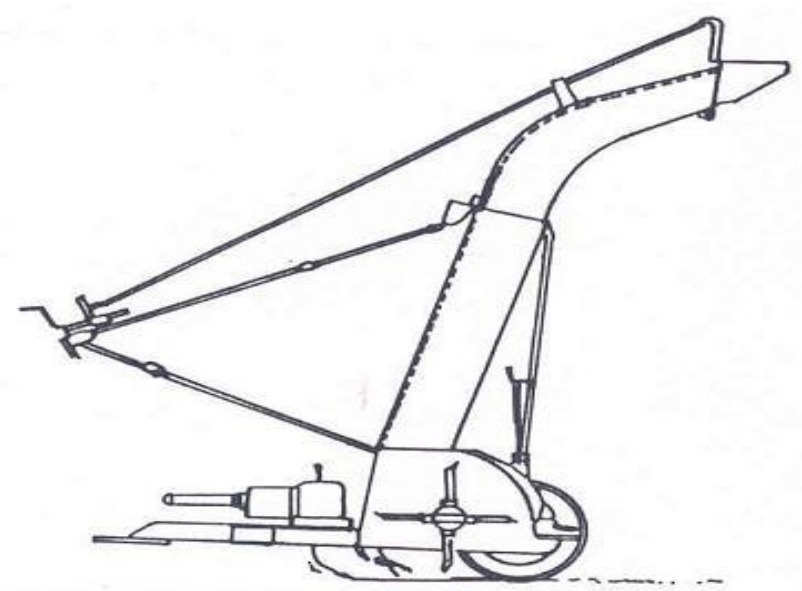

Figure 3: Flail type PTO-driven forage harvester - 2D 
To explain the operation of drum type hay mower, the following graphic may be used.

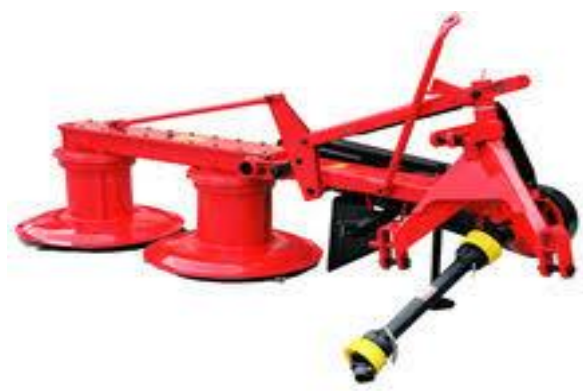

Figure 4: Power flow in a drum mower Transformational graphic (2D)

This project also incorporates labelled diagrams to enhance comprehension as learners can relate to how various parts of a machine relates to each other.

To illustrate the different components of a disc harrow used in seedbed preparation, the following graphic may be used.
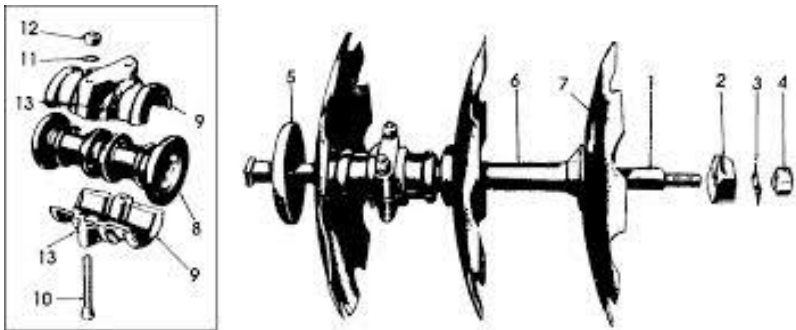

Figure 5: Disc harrow gang assembly - representational graphic

\subsubsection{Videos}

Animation is useful when the content is properly designed such that the learner is involved in active mental processing while viewing the animated document. The document may be a video which is a sequence of real scenes captured using digital camera, web camera or mobile phone. Animation is digital images created from drawn pictures and displayed one after another to create a moving effect. While concluding his research, [17] pointed out that effective animation needs to invoke the five principles namely- apprehension, interactivity, congruence, flexibility and attention guiding principles. Learning may be impaired when irrelevant content is included

\subsection{Types of Learning Management Systems}

\subsubsection{Content Management Systems}

Computer-Based Multimedia learning platform has the following benefits: - flexibility of space and time, personalized teaching \& learning, enhanced learning methods and more concrete learning experiences [18].

Different Content Management Systems are at present accessible. These Systems can be utilized to make, alter, compose, store and distribute content for online/offline record [16]. It can bolster the making, distributing, upgrading, documenting, tracking and recovering of computerized data.

There are subcategories of CMS programming, for example, Web Content Management, Digital Asset Management and Enterprise Content Management [19].
Examples of content Management Systems include: Joomla, Drupal, Alfresco among others.

\subsubsection{Learning Management Systems}

Learning Management System is web-empowered application software with relational database that connects learners to learning content, trainer capability, course guidelines and evaluation techniques [4]. It enables registration of users, tracking of courses and produces various reports to the management [5]. Most of the Learning Management Systems have common features that trainers can use to share learning content as well as enable interaction with their trainees both asynchronously and synchronously [6]. Examples of the Learning Management Systems are Moodle, WebCT, Toolbook, Sakai, Blackboard, TelEduc, TopClass server, among others.

\subsection{Benefits of Cloud Computing in Education}

The National Institute of Standards and Technology (NIST) defined Cloud computing as 'a model for enabling ubiquitous, convenient, on-demand network access to a shared pool of configurable computing resources (e.g., networks, servers, storage, applications, and services) that can be rapidly provisioned and released with minimal management effort or service provider interaction'. The free or low cost cloudbased services such as Twitter, Youtube, Google apps, Drop box among others have been used in education for e-content creation, social interaction and collaboration [16].

\subsection{Challenges of Cloud Computing in Education}

The adoption of Cloud Computing may be faced with myriads of challenges ranging from regular power supply interruption, low and erratic internet connectivity, high cost of equipment maintenance which tends to make the good intention a dream [19]. The challenges outlined above are more prevalent in least developed countries (LDCs) mostly due to poor infrastructure such as internet connectivity and underfunding in learning institutions. Further, most of the trainers in the Least Developed Countries are used to traditional teaching methods and may be reluctant to change. Similarly, learners are used to getting learning materials already prepared by the teachers [20].

\subsection{Research Gaps}

Machinery functionality requires exploded three dimension models and graphics that enhance understanding of the principles of operations that would otherwise be difficult to comprehend. From the literature review, most of the training institutions using Cloud Computing mainly targets arts based and not engineering courses. [21] concurred that most of the courses offered by institutions of higher learning through Learning Management Systems are in the field of humanities,

Business, computing and technology. This Project intents to fill the gap by developing and incorporating e-content that can be used by instructors to teach Agricultural Machinery using multimedia as part of the implementation of Agricultural Engineering curriculum in Sot Technical Training Institute Kenya.

\section{METHODOLOGY}

As the Project aimed at incorporating ICT concepts in teaching Agricultural machinery subject, the researcher adopted Case study approach and purposively selected Sot 
TTI in Bomet County, Kenya for the project. The institution has Smart-board facilities with unlimited internet access.

Due to the small number of students studying agricultural machinery subject, all the 27 students were selected to participate in system testing and a questionnaire administered after two weeks of interaction with the system. Out of the 27 students, 16 were males and 11 females. One instructor was involved from the engineering department. A pretest on engine operation was administered to the students after training using traditional lecture and text approach. They were directed to access e-content on tractor transmission system. After the system interaction, a posttest was administered relating to the transmission system operation. System logs were also extracted to identify e-content mostly accessed by the learners.

\subsection{Content sampling}

Farm machinery was purposively sampled to cover required content indicated in the KICD syllabi available at Sot TTI which included ordinary farm tractor, farm implements such as disc, mouldboard and reversible ploughs, harrows, planters, sprayers, hay machinery, forage and combine harvesters. The content was organized in form of notes, audio visual and videos. The learning content was obtained from text books purposively selected at the Institute library and internet. The data was also purposively selected and organized into notes arranged in topics and presented in pdf. The diagrams were presented in PowerPoint slides with explanatory notes. Audio content was attached through links in PowerPoint. Depending on the desired topic, video editing was done to partition long videos and then uploaded to youtube.com to be accessed through links in PowerPoint in the Sot LMS.

\subsection{System registration}

The researcher logged in to the online Moodle.org website and created Sot LMS with unique features. The researcher then customized the system in the cloud to have institute logo, and registered it as: - http:/sottechnical.moodlecloud.com and the institute site is hosted by MoodleCloud.com free of charge where e-content was uploaded.

\subsection{Course creation}

While logged into the Sot TTI system, the researcher created the Agricultural Engineering course with the necessary requirements.

\subsection{Learning content uploading to the Cloud}

While online and logged in, the researcher turned editing on and selected Agricultural Engineering course. Previously prepared e-content was then uploaded in form of files and folders. Some of the PowerPoint files had links to youtube.com for learners to watch relevant videos.

\subsection{User enrolment}

The users interacting with the system are in three categories; the teachers, the learners and guests. The teachers and the learners needed to be enrolled in the system by the system administrator. The system administrator who in this case was the researcher collected data pertaining to the teachers and learners from the Institute administration. Guests can log into the system without the need of a password.

The researcher enrolled users by putting the following details in the system: - First name, surname, email address, City/town, and gave brief description of the user e.g. lecturer in given fields. The enrolled users were informed to interact with the content by logging in.

\subsection{User Permissions}

After establishing user account in the Sot TTI system, the researcher set login permissions. The following user accounts were assigned to various enrolled system users:

- Student (default -Has fewer privileges within a course and can interact with course content only)

- Teacher with editing permissions (can edit a course with activities/content and provide learner feedback - e.g. grades, assignment comments etc.)

\subsubsection{Teacher interaction with training content}

The subject teacher developed the e-content and uploaded to the system in the cloud. The teacher then guided the learners accordingly to access the content and encourage group discussions, chats and group assignments. The trainer is in a position to edit the content regularly as necessary.

\subsubsection{Learner interaction with learning content}

The learners once enrolled were able to login and access the learning contents either using computers or mobile phones with internet connectivity. It implies that accessibility was anytime anywhere.

\section{DATA PRESENTATIONS, ANALYSIS \& DISCUSSION}

This section outlines the data collected and summarized in tables with analysis given in percentage using Ms Excel. Some representations are further given in graphs and piecharts particularly for comparison.

There were 27 respondents involved in the study. 16 of them were males and 11 females. Subject lecture notes were in form of text in pdf files. Image and text were separately uploaded and the videos were accessible through links.

\subsection{Types of Multimedia}

Table 1: Multimedia preference per gender

\begin{tabular}{|l|l|l|l|l|l|}
\hline Representation & Male & $\%$ & Female & $\%$ & $\begin{array}{l}\text { Total } \\
\%\end{array}$ \\
\hline Text only & 16 & 100 & 11 & 100 & 100 \\
\hline Image and Text & 14 & 87.5 & 10 & 91 & 89 \\
\hline Audio only & 14 & 87.5 & 8 & 72.7 & 81 \\
\hline $\begin{array}{l}\text { Video + Text+ } \\
\text { Image }\end{array}$ & 16 & 100 & 10 & 91 & 96 \\
\hline
\end{tabular}

In table 1 above, the respondents had the highest preference at $100 \%$ for lecture notes in text format. This could be because they could download the same and save in their phones and could print as hand-outs for regular reference. Next in preference was for video + text + image at $96 \%$ which concurs with [12] findings that learners prefer multiple to single presentations. This comprised of $100 \%$ of the male learners and $91 \%$ of the female learners. Next was image and text $(89 \%)$ then audio presentations being the least at $81 \%$. Figure 6 below displays graphically the statistics. 


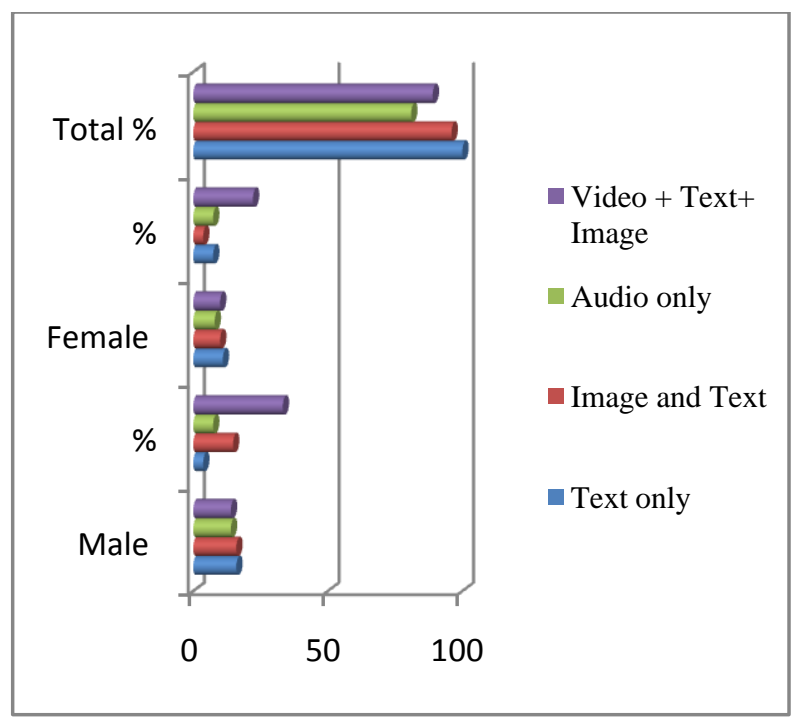

Figure 6: displays graphically the statistics.

\subsection{Identified multimedia}

Basing on the relevance of the available multimedia, the study selected specific content that best convey the concept to be communicated as per the syllabus. The text that was presented in pdf file format enabled the learners to obtain explanations and elaboration on the operation of specific machinery.

Table 2: Sampled e- content developed per size

\begin{tabular}{|l|l|l|l|}
\hline Representation & Skill area & File type & File size \\
\hline Text & Engines & Ms Word & $172 \mathrm{~KB}$ \\
\cline { 2 - 4 } & Engines & pdf & $293 \mathrm{~KB}$ \\
\cline { 2 - 4 } & Gearbox & Pdf & $236 \mathrm{~KB}$ \\
\cline { 2 - 4 } & Ploughs & PPT & $15.8 \mathrm{~KB}$ \\
\cline { 2 - 4 } & Final Drive & Pdf & $293 \mathrm{~KB}$ \\
\cline { 2 - 4 } & Sprayers & pdf & $215 \mathrm{~KB}$ \\
\cline { 2 - 4 } & Planters & pdf & $195 \mathrm{~KB}$ \\
\hline Image & $\begin{array}{l}\text { Forage } \\
\text { harvester }\end{array}$ & JPEG & $15.8 \mathrm{~KB}$ \\
\cline { 2 - 4 } & Gearbox & PNG & $24 \mathrm{~KB}$ \\
\cline { 2 - 4 } & Mower & JPEG & $8.32 \mathrm{~KB}$ \\
\cline { 2 - 4 } & $\begin{array}{l}\text { Combine } \\
\text { harvester }\end{array}$ & PNG & $57.0 \mathrm{~KB}$ \\
\hline Videos & $\begin{array}{l}\text { Diesel } \\
\text { engine }\end{array}$ &. $\mathrm{Mp} 4$ & $578 \mathrm{Mb}$ \\
\cline { 2 - 4 } & $\begin{array}{l}\text { Petrol } \\
\text { engine }\end{array}$ &. $\mathrm{Mp} 4$ & $61.5 \mathrm{Mb}$ \\
\cline { 2 - 4 } & $\begin{array}{l}\text { 2-stroke } \\
\text { engine }\end{array}$ &. $\mathrm{Mp} 4$ & $145 \mathrm{Mb}$ \\
\cline { 2 - 4 } & $\begin{array}{l}4-\text { stroke } \\
\text { engine }\end{array}$ &. $\mathrm{Mp} 4$ & $120 \mathrm{Mb}$ \\
\cline { 2 - 4 } & $\begin{array}{l}\text { Reversible } \\
\text { ploughing }\end{array}$ &. $\mathrm{Mp} 4$ & $37.9 \mathrm{Mb}$ \\
\cline { 2 - 4 } & Hay baling &. $\mathrm{Mp} 4$ & $24.6 \mathrm{Mb}$ \\
\hline
\end{tabular}

\begin{tabular}{|l|l|l|l|}
\hline & Gearbox & .avi & $85 \mathrm{Mb}$ \\
\hline
\end{tabular}

From table 2 above, the e-content was arranged as text equivalent to $1.42 \mathrm{Mb}$ size. The text content was organized as per the topics outlined in the syllabus. Images were presented in JPEG \& PNG formats of $1.05 \mathrm{Mb}$. This was necessary as it complemented the explanatory text lecture notes relating operation of the specific machinery. Similarly, videos taking 1.139 GB could be accessed in the system in the cloud. Some of the images and videos in the system were incorporated as PowerPoint and Ms Word files with links to the internet. Together with hands-on practical approach in the College workshop, the learners were able to demonstrate better understanding of the operation of the given machinery.

\subsection{Appropriate LMS}

Table 3: Ease of use of the Sot LMS by the respondents

\begin{tabular}{|l|l|l|}
\hline & Number of students & Total \% \\
\hline Difficult & 4 & 14.8 \\
\hline Moderate & 6 & 22.2 \\
\hline Easy to access & 17 & 63.0 \\
\hline
\end{tabular}

The questionnaire captured the response of the enrolled users after interacting with the system whether it was difficult, moderate or easy to use. From table 3 above, more than half of the students $(63.0 \%)$ indicated that they found the Sot Learning Management System easy to use. This finding concurs with [1] that Moodle software is easy to use $22.2 \%$ indicated system use as moderate. Only $14.8 \%$ found the system difficult to use. However, this could be due to computer literacy level and not necessarily the system. The graph below summarizes the findings.

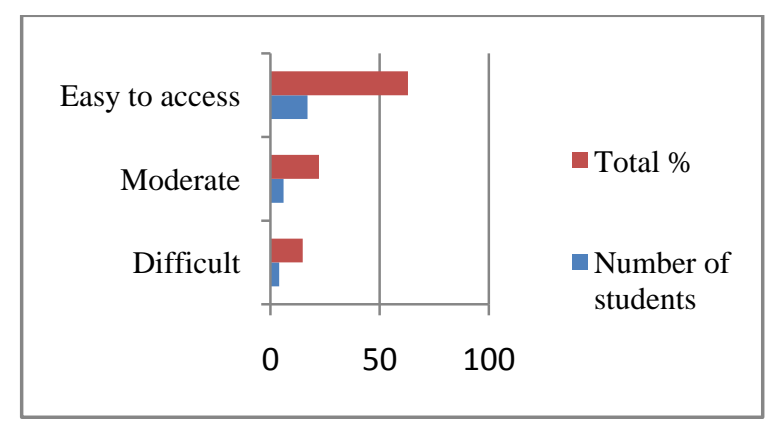

Figure 7: A comparison the ease of use of the Sot LMS

\subsection{Functionality of the adopted LMS}

Table 4: Pre-test and post-test performance

\begin{tabular}{|l|l|l|}
\hline & Pretest & Posttest \\
\hline Mean score (\%) & 68 & 76 \\
\hline
\end{tabular}

Table 4 above indicates the mean score attained before and after being exposed to e-content in the LMS. After the students had interacted with the system as directed, the posttest was administered and they achieved a mean score of $76 \%$ which was higher than the $68 \%$ mean score for the pre-test. This could be attributed to the fact that the animations which they were advised to access elaborated the operation of the transmission system such that by the time of the post-test, they had better comprehension. Figure 8 below gives comparison of the performance. The variation may not be so much but instructional learning platforms enhance learning satisfaction compared to traditional teaching methods and this 
is in line with the findings by [18]. The pie-chart in figure 8 below gives the comparison of the performance.

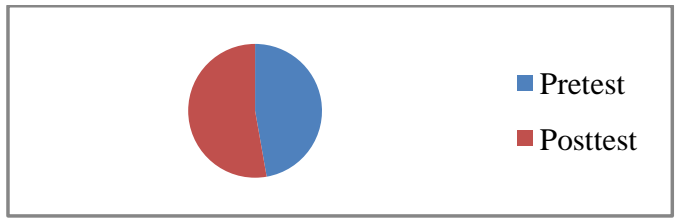

Figure 8: A comparison of pre-test and post-test performance

Table 5: e-content accessed by the respondents

\begin{tabular}{|l|l|l|}
\hline & Number of students & Total \% \\
\hline Text & 27 & 100 \\
\hline Videos & 24 & 89 \\
\hline Other e-content & 14 & 52 \\
\hline
\end{tabular}

Table 5 above shows the type of e-content the respondents were able to access in the Sot LMS. All the learners (100\%) who logged in accessed the text content that was in pdf format. This could be due to the fact that they were familiar with lecture notes approach and were more comfortable in having them in their phones. Also $89 \%$ proceeded to follow the links and watched videos and animations in YouTube. This is also in agreement with [12] findings that learners prefer multiple to single presentations. It also affirms that animations make learning interesting [21]. Only slightly more than a half $(52 \%)$ took more time to access other content in the e-Library. The pie-chart in figure 9 below outlines the comparison.

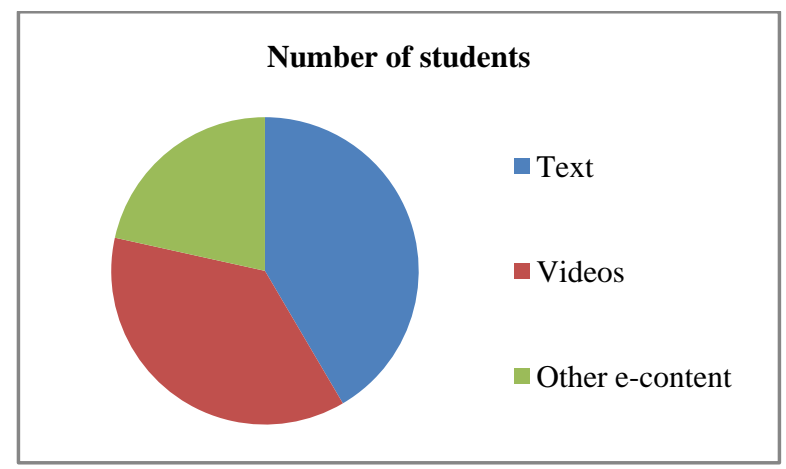

Figure 9: A comparison of e-content accessed by students

Table 6: Means of access to the Sot LMS by the respondents

\begin{tabular}{|l|l|l|}
\hline & Number of students & Total \% \\
\hline Personal Phone & 17 & 63.0 \\
\hline Personal Laptop & 1 & 3.7 \\
\hline College Computer & 9 & 33.3 \\
\hline
\end{tabular}

From table 6 above, more than half of the students $(63.0 \%)$ indicated that they accessed the Sot LMS using their mobile phones. This implies that they are able to interact with the econtent anytime anywhere. Similarly $33.3 \%$ of the respondents were able to access the learning content through the college computers. This also implies that majority (96.3\%) of the students are making use of the college internet connectivity. Only one student had personal laptop. Figure 10 below gives the comparison.

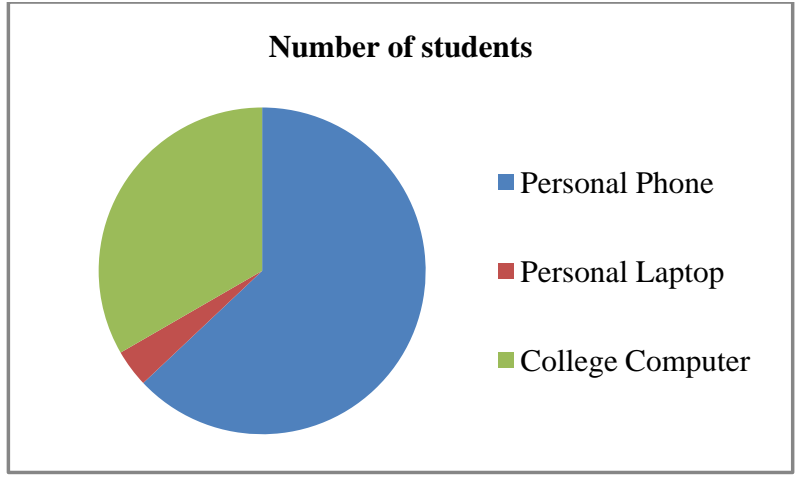

Figure 10: A comparison of means of access to the Sot LMS by the respondents

\section{SUMMARY OF FINDINGS, CONCLUSION AND RECOMMENDATIONS}

\subsection{Summary of major findings}

This section presents a summary of major findings of the study.

\subsubsection{Summary of the multimedia that can be used in teaching on the operation of agricultural machinery.}

The Project found that blended approach of combining traditional teaching methods and multimedia technology enhances comprehension of machinery operations.

\subsubsection{Summary of identified multimedia for} teaching on the operation of agricultural machinery

The study identified combination of various forms of media such as text, graphics, audio (including speech), animation and video together with interactivity to produce presentations and communicate engineering concepts is essential. [2-3].

\subsubsection{Summary of appropriate Learning} Management System for teaching on the operation of agricultural machinery through cloud computing

Moodle Learning Management System was identified as the most appropriate for the Project as it has various user access/control possibilities, user friendly, advanced backup tools with free cloud-hosting facility.

\subsubsection{Summary of the functionality of adopted LMS at Sot TTI}

The Project was registered with Moodle.org and enrolled users interacted with e-learning content, classmates and among themselves. The system was fond to be user friendly as noted from the respondents.

\subsection{CONCLUSION}

The objectives of the Project were to study the use of multimedia to enhance comprehension of the operating principle of diverse agricultural machinery, identify appropriate multimedia, and select appropriate Learning Management System as well as to test the functionality of the adopted system as used in teaching Agricultural Machinery subject. From the user responses, it was noted that the above objectives of using multimedia in teaching agricultural machinery subject were achieved. 
The fact that most students had internet access, the benefit of faster communication between teachers and learners was noted as they could easily share course work updates.

\subsection{Recommendations}

From the findings, the study recommends as follows: Firstly, since free hosting has limited number of allowable enrolled users and limited capacity in terms of possible e-content that can be uploaded, hence Sot TTI is encouraged to subscribe for scalability and continued use. Secondly, given that the provided video links enable users to view related content, there was need to have user training on the part of the users and guidance on the learners so as not to be detracted by other irrelevant internet content. Thirdly, there was the challenge of some phones not being able to open certain files due to limited functionality. Mobile phones manufacturers therefore need to come up with affordable and compatible phones.

\subsection{Suggestions for further research}

The study recommends the following further studies. This project was limited to the stated subject excluding other engineering subjects under TVET programs. Further research can be conducted to establish the functionality of the system in related fields and identify the features which may need improvement given that Moodle is open-source software. A study can also be undertaken to determine the effect of teaching Agricultural Machinery through cloud computing on academic performance.

\section{ACKNOWLEDGEMENTS}

The authors wish to acknowledge the administration, staff and students in the department of Applied Sciences in Sot Technical training Institute for their support during the study.

\section{REFERENCES}

[1] Cigdem, C., \& TIRKES, G. (2010). Open Source Learning Management Systems in Distance Learning. The Turkish Online Journal of Educational Technology,

[2] Li, Z., \& Drew, M. S. 2004. Fundamentals of Multimedia. Pearon Education International.

[3] Basic, C. (n.d.). Media , Multimedia \& Digital Media. ExplorNet Career Tech from the Centres of Quality Teaching

[4] Phillipo, B. J., \& Krongard, S. 2012. Learning Management System ( LMS ): The Missing Link and Great Enabler.

[5] Reme`, R. 2005. Learning Management System. In WDS'05 Proceedings of Contributed Papers, Part I,

[6] Vovides, Y. et al., 2007. The use of e-learning course management systems to support learning strategies and to improve self-regulated learning, Educational Research Review,

[7] Gupta, S. What is Multimedia? AP-CSE, NIEC.

[8] Jabbour, K. K. 2012. Multimedia in Teaching Lessons, Acta Didactica Napocensia ISSN 2065-1430.

[9] Montessori, M 1912. The Montessori Method, New York

[10] Molnar, G. (2007). New ICT Tools in Education Classroom of the Future Project.

[11] Digiacinto, D. (2007). Using Multimedia Effectively in the Teaching-Learning Process. Journal of Allied Health.

[12] Pastore, R. (2016). Learner Preferences in Multimedia Design. Journal of Multimedia Processing and Technologies.

[13] COL. (2003). A Handbook for Teacher-Developers. (U. V. Reddi \& S. Mishra, Eds.). New Delhi.: Commonwealth Educational Media Centre for Asia.

[14] Sky-mcilvain, E. (2009). Education for an Information Age. Teaching in the Computerized Classroom, 7th edition, 235-264.

[15] Mayer, R. E., \& Moreno, R. (2002). Animation as an Aid to Multimedia Learning, 14(1), 87-99.

[16] Clark, R. E., Choi, S., \& Hall, W. P. (2005). Five Design Principles for Experiments on the Effects of Animated Pedagogical Agents. Journal of Educational Computing Research,

[17] Betrancourt, M. The Animation and Interactivity Principles in Multimedia Learning, Geneva University.

[18] Tsung, B. (2010). Educational Benefits of Multimedia Skills Training. TechTrends, 54, Number 1(February).

[19] Yadav, K. (2014). Role of Cloud Computing in Education. International Journal of Innovative Research in Computer and Communication Engineering,

[20] Akin, O. C., Fagbola, T. M., \& Daramola, C. Y. (2014). The Impact and Challenges of Cloud Computing Adoption on Public Universities in Southwestern Nigeria. International Journal of Advanced Computer Science and Applications,

[21] Adhiambo, B., \& Okeyo, G, Cheruiyot W. (2017). Framework for Improving Usability of Learning Management Systems by Integrating Pedagogical Agent. International Journal of Computer Applications. 